Farber's Reimagined Mad Pride:

Strategies for Messianic Utopian Leadership

\begin{abstract}
:
In this article, I explore Seth Farber's critique, in The Spiritual Gift of Madness, that the leaders of the Mad Pride movement are failing to realize his vision of the mad as spiritual vanguard of sociopolitical transformation. First, I show how, contra Farber's polemic, several postmodern theorists are well suited for this leadership (especially the Argentinian post-Marxist philosopher Ernesto Laclau). I reinterpret the first book by the Icarus Project, Navigating the Space between Brilliance and Madness, by reimagining its central metaphor of Icarus. And I conclude with four strategies for higher functioning mad folks to transform our penitentiary world.
\end{abstract}

KEYWORDS: madness; The Icarus Project; Ernesto Laclau; Sascha DuBrul

Dissident psychologist Seth Farber's The Spiritual Gift of Madness: The Failure of Psychiatry and Rise of the Made Pride Movement makes a valuable attempt to extend the c/s/x (consumer/survivor/ex-patient) movement and Mad Pride movement into a broader program for sociopolitical transformation. In brief, following R. D. Laing's The Politics of Experience, Farber interprets those labeled "psychotic" as a spiritual vanguard for what Farber calls “messianic utopianism” (and which I parse here as "mad messianic utopianism”) More specifically, Farber argues that one of the most prominent leaders of the Mad Pride social justice movement has the potential to become the leader of his movement—but only provided that his organization repudiates all use of psychiatric medications. Unfortunately, Farber's three-pronged polemic (against psychiatry, prominent leaders of Mad Pride, and what he terms "the secular postmodern pluralist zeitgeist") weighs down his text, obscuring his provocative proposal, and potentially alienating other, more viable candidates for his movement.

Seeking to find a way around this impasse, the present investigation proceeds in the following three steps. First, I show how, despite Farber's polemics against postmodernism, that tradition includes several theorists (most promising among which, in my view, is the Argentinian post-Marxist philosopher Ernesto Laclau) whose work implies several strategies that might be 
effective for leaders of the Mad Pride movement. Second, I reinterpret the first book by the foundational grassroots Mad Pride organization, namely the Icarus Project, entitled Navigating the Space between Brilliance and Madness: A Reader and Roadmap of Bipolar Worlds (hereafter, "Navigating"), more specifically by reimagining their metaphor of Icarus in the context of late capitalism as a prison world. And finally, I sketch a scenario based on this reinterpretation, deriving therefrom four strategies that might more effectively bring Farber's mad messianic utopianism closer to realization.

For any readers unfamiliar with the Mad Pride movement, it can be helpfully understood as one branch of the late twentieth-century wave of social justice movements, and arguably even as a subgenre of the disability rights movement focused on what are sometimes conceptualized as psychological disabilities. This connection is attested by the opening epigraph to Chapter 2 of the recent (2017) anthology, Community Mental Health: Challenges for the 21 st Century: “NOTHING ABOUT US WITHOUT US!! (Protest poster outside American Psychiatric Association) (Rosenberg 2017, 19). Apropos of the present investigation, and Farber's critique discussed herein, this chapter is cowrote by the two founders of the Icarus Project, Sascha Altman DuBrul and Jacks McNamara. Moreover, as also attested by the latter two leaders of Mad Pride, this movement also explicitly modeled itself on the LGBT+ movement, in part because some of the founders were also part of that struggle, and saw relevant similarities between the two movements.

Although there has been an unfortunate neglect, within the academy, of these theoristactivists, thanks to the pioneering work of scholars such as the philosopher, radical psychiatrist, and self-identified mental health consumer Bradley Lewis, this is starting to change. For an example from the pages of Journal of Medical Humanities itself, they recently (2014) published 
a journal article by DuBrul summarizing the history of Mad Pride, the Icarus Project, and his own role therein, which I would strongly recommend for more detailed background information relevant to both Farber's critique and the remainder of the present investigation.

Nevertheless, such materials, perhaps precisely because they were written/edited for inclusion in an academic journal, lack some of the features that have made The Icarus Project's earlier texts to powerful and influential. More specifically, the latter texts include a blending of genres and media, including autobiography, poetry, drawings, and collage, which create a multisensory, surrealist/magic realist feel that is essential for rendering phenomenologically the firsthand experience of extreme mental states. It is a bit like the difference between reading an academic encyclopedia article on Nietzsche as opposed to Thus Spoke Zarathustra. It is in part for this reason that Navigating recently (2015) celebrated its tenth anniversary edition, and that it inspired my concluding scenario and its four proposed strategies for leaders of Mad Pride today.

\section{Farber's Mad Messianic Utopianism}

In the Preface of The Spiritual Gift of Madness, drawing inspiration from what Martin Luther King, Jr. calls "creatively maladjusted" persons, Farber challenges the Mad Pride movement to "fulfill its potential," namely to "abjure the secular postmodern zeitgeist and affirm instead a fully spiritual messianic vision of madness and social change," in alliance with other “neomessianic [sic] forces (e.g., New Age)" (Farber 2012, xxi-xxii). The reason that Mad Pride is crucial for this effort, Farber claims, is that "mad persons have a distinctive contribution to make to the salvation of the planet" (xxii). Put simply, Farber argues that mad people's most distinctive trait is spirituality, manifested in the common theme among "psychotic" expressions of transcendent cosmic connectedness and wholeness. Nothing short of the latter, in Farber's 
view, will suffice to overcome what he regards as the most urgent crisis of our time, namely global climate change.

To support his contention that Mad Pride is uniquely qualified to take the lead on the crisis of climate change, in Farber's "Introduction" he puts the movement in historical perspective. Mad Pride, he writes, is "a recent outgrowth of the larger mental health liberation movement — now called the psychological survivors' movement — that originated in the early 1970s" (Farber 2012, 1). Despite being a relative latecomer, however, Mad Pride has become a large movement on its own, in part because the number of people diagnosed as psychotic has mushroomed in recent years. "According to the National Institute of Mental Health," Farber notes, "over eight million Americans have bipolar disorder or schizophrenia, the two most common forms of "psychosis"' (1).

Against this background, and turning from Mad Pride's present to its future, Farber asks, "Will it spread its wings and become a movement based on an affirmation of the holiness of the Earth, of the preciousness of all sentient life, of the freedom of the spirit, of the fraternity of humanity, of the sanctity of the imagination?” (Farber 2012, 1). In an initial response to this question, I would note that, of the five key phenomena affirmed here (namely holiness, preciousness, freedom, brotherhood, and sanctity) most are represented in various forms of continental and Marxist theory. For example, if fraternity is modified to something like "siblinghood," then it becomes compatible with most forms of humanism, and freedom of the spirit (especially in French's esprit) remains a vital concern of various Nietzsche-inspired philosophies.

To prod Mad Pride in his preferred direction, Farber's The Spiritual Gift of Madness features interviews that analyze what he describes as "the heroic triumphs of six mad persons, 
each of whom can pass as normal today, all but one of whom do not take any psychiatric 'medication,' and all of whom far exceeded the low expectations of conveyed to them by Psychiatry" (Farber 2012, 2). Problematically, however, the one exception to this group (the one who, at the time of the interview, is taking psychiatric drugs) is also the most influential, including for Farber, namely Sascha DuBrul. The fact that Farber's preferred icon for his reimaging of Mad Pride violates the central exemplar prohibition of that reimagining (namely, taking psychiatric drugs) suggests that a more effective general strategy for realizing Farber's vision might be to shift from identifying specific leaders to instead thinking about the strategies that might assistant any leader in the movement in realizing Farber's dream. ${ }^{1}$

Farber's desired transformation of Mad Pride from a civil rights movement to a psychopolitical revolutionary movement relies on a cluster of conceptual distinctions that he finds, in his words, “implied in R. D. Laing's work, particularly in The Politics of Experience” (Farber 2012, 3). To wit, Farber redefines (1) "insanity" as "a state of spiritual derangement," (2) "sanity" as "a condition in which one is accordance with spiritual growth," and (3) "madness" as referring "nonpejoratively [sic] to 'altered states of consciousness' (ASC) that are nonrational" (3). Fleshing out these redefinitions, Farber notes that madness "can be either good or bad or neither," altered states "are potentially valuable experiences," and by these "definitions one could thus be both mad and sane" (3).

To prevent misunderstandings of these redefinitions by Farber, I interpolate here two clarifications. First, Farber uses "spiritual" very broadly, to include any sense of connectedness with a transcendent reality, which is roughly equivalent to its dominant New Age use. Thus, for example, "sanity" for Farber does not require religiosity, let alone theism, but merely a looser

\footnotetext{
${ }^{1}$ I am indebted, for the second point, to an early reviewer of the present article.
} 
sense of spirituality. Second, as Farber later clarifies, he does "not mean messianism in any fundamentalist sense of the term" (Farber 2012, 17). Instead, Farber aligns himself with Martin Buber's more including conception thereof, and indicates that he uses the terms "messianic" and "utopian" in this text interchangeably (which he justifies with the claim that the Marxist philosopher Ernst Bloch "showed them to be the same phenomenon") (17). In this way, Farber's "messianic" comes closer to that of Jacques Derrida, notwithstanding Farber's strident rejection of postmodernism, as well as Derrida's rejection of the equivalence of the two terms.

Like Laing in The Politics of Experience, Farber then mounts an extended attack on contemporary normality. "The persons I call 'insane'," he begins, "are most likely to be very well-adjusted people" (Farber 2012, 4). Moreover, such normal "insanity" can also result in what Farber terms "evil acts"- but only if those insane acts also "include an element of absurdity or what I call objective unintelligibility" (4). For example, Farber claims that "the United States is a society in which our political and business leaders either deny or ignore ecological threats and promote practices that unless stopped could lead, according to our best climate scientists, to the annihilation of life on Earth" (4). Though our leaders perhaps bear the greatest responsibility for this ecological injustice, in Farber's view, everyone who merely passively accepts US evil is also to varying degrees morally culpable. "Many people," Farber notes, "have adjusted to our insane society because they do not have the spiritual maturity and courage to fight against it," or "because they—understandably—feel hopeless" (4).

This brings Farber to one additional crucial redefinition. "The antonym of insane is not sanity," he begins, because sanity "is a neutral term, but [rather] wisdom, which is a higher sanity" (Farber 2012, 4). More precisely, Farber asserts, wisdom "is highly intelligible, it possesses a plenitude of meaningfulness" (5). For this reason, and here Farber returns to the 
messianic rhetoric he prefers for describing Mad Pride, "Our greatest prophets are always men or women of wisdom — of a higher sanity — who are invariably critics of our insane society" (5). In support of this point, I note Plato's etymological tracing of the concept of "manic" to mantike, the Greek word for prophecy.

With this political-philosophical background in place, Farber then returns to a more detailed history of Mad Pride, noting that it "was officially launched in England in 1999 with the foundation of the organization Mad Pride, which soon spread to the United States" where, three years later (in 2002) it "found institutional embodiment with the formation of the Icarus Project" (Farber 2012, p. 5). The goals of this institutionalized movement, according to Farber, "are empowering the mad and, more broadly speaking, effective profound changes in society" (5). This historical overview raises the issue of the movement's underpinnings.

On the one hand, Farber claims, Mad Pride's "philosophical emphasis is on the distinctiveness of the mad" (Farber 2012, 5). On the other hand, the movement "acknowledges the interconnectedness and the existential equality of all groups" (5). This foundation, Farber explains, marks a major change from Mad Pride's parent movement, the psychiatric survivors' movement, whose foundation "was established by psychiatrist Thomas Szasz, who (a) argued that "mental illness was a myth," (b) "opposed the insanity defense," and (c) "rejected the existence of madness and thus of Mad Pride" (5). For readers familiar with contemporary social justice movements, a familiar pattern can be found here. To wit, the movement's first generation emphasizes the inherent equality between its own disempowered group and the empowered majority, seeking integration therewith (like the suffragettes and Civil Rights protestors). Then the second generation emphasizes their group's distinctiveness, rejecting integration as entailing conformism to vice (like cultural feminists and Black Power activists). 
Moving forward in history, from Szasz and the survivors' movement to Laing and Mad Pride, Farber claims that The Politics of Experience was Laing's “most important book," which "prefigured the ideas of the Mad Pride movement that first arose three decades later" (Farber 2012, 6). Crucial there, for Farber is the "radicalism" of Laing's claim that "the mad were superior in certain important respects to normal people" (6). Farber also criticizes Mad Pride's current noteworthy leaders, including DuBrul, because in the movement's circles, 'Laing is rarely mentioned or even read" (7). This is harder to forgive, for Farber, insofar as he views Mad Pride as "based on the Laingian theme" of "the distinctiveness of the mad" (7).

Farber omits here, however, Laing's own subsequent backtracking on this point, and his explicit repudiation of the views in The Politics of Experience. This point seems particularly salient for Farber's analysis, given that Laing's repudiation anticipates DuBrul's repudiation of his own Laingian views. Moreover, it strikes me as ethically/politically problematic that Farber, who does not identify as "mad" (as far as I am aware, and certainly not in the text in question), is criticizing the Icarus Project's leaders — who do self-identify as mad-for not referring to the work of Laing — who, like Farber, does not identify as mad — and for instead coming to their own conclusions, similar to Laing's, about madness based on their firsthand experience. One can easily map this onto the classic problematic, identified by Foucault among others, in which a member of the psychiatric/psychological establishment (Laing was a psychiatrist, and Farber is a therapist) denies legitimacy to a member of the community already stigmatized as "mad" for failing to conform to their own institutional practices and truth-procedures.

On this note of self-identification, Farber then observes that there are two traditions to which leaders of Mad Pride (including DuBrul) have explicitly appealed. "The founders of Mad Pride both in England and in America," Farber relates, “often drew an analogy between Gay 
Pride or Black Pride and Mad Pride" (Farber 2012, 7). As with these two second waves of social justice movements, Mad Pride attempts to valorize its group's differentiating characteristic in its own right, which for Farber is encapsulated most eloquently in Sascha DuBrul's notion of "dangerous gifts" (7). The latter, Farber notes, eventually "became a shibboleth for the perspective of The Icarus Project" (7).

Also analogously to LBGT+ Pride and Black Pride, Mad Pride activists argue for the existence of a "conformist bias" in mainstream culture. In the case of Mad Pride, the perpetrators of this bias include "mental health professionals," whose prejudice "manifests itself in an inability to appreciate the communal, the cooperative, the nonrational, and the spiritual or religious" (Farber 2012, 8). In other words, Mad Pride's leaders, in Farber's view, tend to identify more with other activists (a) whose embodiment and social position expose them to oppression from mainstream society, and (b) who often prioritize reducing the suffering and injustices in their communities relative to other issues that are more urgent for their relatively more empowered allies (such as climate change for non-mad-identifying allies like Farber).

Returning from this detailed history to the present, and actively repositioning the figures in The Spiritual Gift of Madness as leaders in Farber's mad messianic utopianism, he describes his interviewees as "the protagonists and heroes or heroines of this book" (Farber 2012, 8). These heroic figures, he continues, "repudiated the mentally ill identity" and became "creatively maladjusted," thus confirming Farber's "theory that the mad constitute a vanguard in the effort to bring change to an insane world" (8-9). Or, using the term Farber borrows from Laing, our world is "ontologically off-course" (9). To course-correct for this, Farber adds, would require what he identifies as "the implicit if not explicit goal of Mad Pride," namely "a transformation of society as a whole" (10). Just as black folks must change white folks to reduce or overcome racism, so 
the mad must change the non-mad to overcome the psychological ableism of today's world. More precisely, in Farber's view, this transformation requires a conception of the mad as prophets. The obstacle he sees to this, citing Foucault, is that "The budding prophets of today are captured, 'cured,' and transformed into chronic mental health patients by the psychiatric system before they have the opportunity to complete the death and rebirth process, to flower into prophets" (Farber 2012, 10).

As I have explored elsewhere, however, there is also an alternate conception of prophecy in the Judeo-Arabic tradition, offered by thinkers such as Abu Nasr Alfarabi and Baruch Spinoza, that can be deployed today for psycho-political transformation. ${ }^{2}$ Perhaps in recognition of this possibility, Farber later pivots, for further support of his vision, to a dissident psychiatrist. John Weir Perry, as Farber relates, "believed that visionaries, prophets, and mad persons are able to descent into the deepest levels of the unconscious and access new myths that guide societies in making transitions in times of crisis" (Farber 2012, 13). As to Perry's evidence for this view, Farber relates that “'almost universally' within 'acute psychosis' lies a messianic vision of a new world order based on 'equality and harmony, tolerance and love" (14). As Farber summarizes, "Perry found in the 'messianic ideation' of his psychotic clients" and "in their 'vision of oneness' a prefiguration of the new society" (14). Farber then quotes both Laing and "the utopian socialist and neo-Marxist theoretician Ernst Bloch" to support his conclusion that "the sociobiological function is often experienced by the mad as a 'calling' to act as catalysts of spiritual evolution, of a messianic transformation" (15).

Unfortunately, in Farber's view, both DuBrul and McNamara, who once "spoke in terms very similar to my own," later "reversed" themselves (16). More specifically, DuBrul, "citing the

\footnotetext{
${ }^{2}$ See Joshua M. Hall, "Neuromancer through Alfarabi: On Neurotics as Politically-Imprisoned World Creators," Parasol: The Journal for the Centre for Experimental Ontology 1 (2017).
} 
influence of Eastern spirituality, repudiated in 2008 the Dionysian-messianic vision he had developed over the previous years; he feared it encouraged egotism" (Farber 2012, 17). Farber later offers the following response to DuBrul's concern:

what is striking to me in the comments of the mad are the absence of arrogance (of 'narcissism' as the shrinks call it)—in fact the humility_-with which these feelings are shared on the Icarus Project forum and the profound philosophical insights expressed by these mad people (Farber 2012, 27).

Though I agree with Farber's assessment of the formal pieces in Navigating, many of them were originally written (or later edited) while on psychopharmaceuticals. Moreover, DuBrul and McNamara close their book by emphasizing the facts that (a) they were both taking lithium the entire time that they were writing it, and (b) it represents the most creative output of their lives to that point. Finally on this point, although this humility can be found in some of the book's contributors' retrospective accounts of things that they said during extreme episodes, others of their examples in the book do not fit that description. The latter category includes multiple examples of individuals claiming to be the messiah, and to be the "center of the universe," to which I will return below.

In short, Farber perhaps illegitimately invalidates a legitimate fear expressed by (among many others) DuBrul, specifically by suppressing legitimating counterevidence from DuBrul's own experience. If so, this is arguably another instance of a problematic comportment toward firsthand accounts of mad folks by a non-mad psychological practitioner. Further support for the legitimacy of this fear can be seen in the fact, as noted by Farber, that "Some of the activists in Mad Pride tend to distrust the very idea of leadership" (Farber 2012, 22). He relates, for 
example, that the fourth member to join the Icarus Project, Madigan Shive, "wrote me in 2009 to warn me against making a hero of DuBrul" (22).

In response to this type of criticism, Farber insists that “one person's life can be changed by reading or hearing the story of another person who 'beat the odds'," and that "The denigration of individual narratives often derives from a collectivist ideology, which I consider repressive" (Farber 2012, 22). He immediately demurs from further comment, however, claiming that "a discussion of this is beyond the scope of this book" (22). For my part, I would suggest that there is significant middle ground between what one might call "atomized individualism" (the normalized pathology of the U.S. today) and "anti-individual collectivism" (the normalized pathology exemplified, perhaps, in Stalin's USSR). Furthermore, this middle ground is currently being occupied, by various theorists who recognize subjectivity or subject positions as relational but real, and who affirm individual narratives as contextualized by individuals' embodiment and social positioning.

Perhaps in recognition of this potential alliance, Farber then extends an olive branch to the same postmodern philosophers whom I have in mind.

Radical deconstruction is salutary, I submit, but only if it is complemented by the commitment to an overall vision of redemption, a vision of the unification of spirit and nature, of conscious and unconscious, male and female, sanity and madness, body and soul, the sacred and profane-as envisioned by the Western Romantic philosophical tradition or by Sri Aurobindo or Christianity at its best" (Farber 2012, 23).

Though there are elements of this claim that I would prefer to revise, I am sympathetic to its overall spirit. 
My preferred formulation would be as follows: deconstruction is incomplete without reconstruction, in the sense of the latter word found in (among other loci) the work of John Dewey and in the Black Reconstruction movement. There is no need for force, I suggest, if one deconstructs the dichotomies of male/female and body/soul, recognizing the fluidity of gender and the complex interpenetrations between what we think of as body and soul. In short, though communities are, and should be, heterogenous and complex, we can build coalitions therein without reducing differences. For this reason, reconstruction does not in fact require, as Farber claims it does, a "virtual obliteration of any kind of unifying Romantic narrative" (Farber 2012, 23). In fact, there is great potential for recuperating Romanticism in postmodernism, including in new readings of Marx and the post-analytic philosopher Stanley Cavell. Nor does every form of postmodernism require a rejection of "the redemptive-messianic vision in general" (23).

Consider, for example, my above invocation of Derrida's conception of the messianic (23). An even more compatible channeling of Derrida's conception toward sociopolitical transformation can be found in Laclau, whose work adapts the concept of "hegemony" from the World War-era Italian Marxist philosopher Antonio Gramsci to unite workers with the subjects of twentieth-century social justice movements into a new leftist populism. ${ }^{3}$ In a second example of potentially-meaningful connection via Laclau, he is also affirmed by the one contemporary postmodern theorist whom Farber offers qualified praise, Bradley Lewis. While Farber objects to Lewis' postmodernism, he nevertheless praises his book, Moving beyond Prozac, DSM, and the New Psychiatry, as "probably the most trenchant and brilliant critique of Psychiatry and scientistic (not scientific) propaganda written since the original works of Szasz and Laing" (Farber 2012, 24n).

\footnotetext{
${ }^{3}$ For more on Laclau, see Joshua M. Hall, "Toward a Salsa Dancing Hegemony: Dancing-with Laclau-with Derrida," Performance Philosophy (forthcoming).
} 
Of particular importance to the present investigation, Laclau affirms (citing Derrida citing Kierkegaard) that there is a "moment of madness" in the decisions that structure our political identities and realities. "The moment of the decision, the moment of madness," Laclau writes, "is this jump from the experience of undecidability to a creative act, a fiat which requires its passage through that experience" (Laclau 1996, 54). Laclau even goes so far as to connect this to theism. "We, 'mortal gods' = those who have to fill the gaps resulting from the absence of God on earth, simulating being Him and replacing with the madness of our decisions an omniscience that will always elude us" (56). Laclau qualifies this, however, by adding that "This madness of the decision is, if you want, as all madness, a regulated one" (57). Going further, he affirms that "The highest form of rationality that society can reach is that of a regulated madness" (58). Finally on this point, in a sympathetic response to Laclau in the same collection, Derrida affirms “there is no ethico-political decision or gesture without what I would call a 'Yes' to emancipation, to the discourse of emancipation, and even, I would add, to some messianicity" (82). Even in this brief summary, Laclau's potential as a postmodern resource for leaders of the Mad Pride movement today seems clear.

\section{Navigating The Icarus Project's Maps and Angels}

Having charted some surprising moments of convergence between Farber and postmodern philosophy (especially Laclau), and even discovered some potential allies for his project of mad messianic utopianism, I will now my own postmodern-influenced reinterpretation of The Icarus Project's groundbreaking book, Navigating the Space between Brilliance and Madness, finding implied therein a cluster of strategies and traits that might be beneficial for leaders of Farber's reimagining of Mad Pride. 
For readers unfamiliar with the book, here is how DuBrul describes its impact on the larger mad community:

After this publication, The Icarus Project grew in earnest. Our website became increasingly well know; our book was in its third printing; and we had completed three incredibly successful tours. Our Icarus discourse of dangerous gifts was becoming audible among the larger community around us, despite our subcultural backgrounds and unorthodox messages, we were onto something that people found compelling. We had tapped into a desperate need for a more creative look at mental health and wellness. The biopsychiatric model, though incredibly profitable for some, left many of us out in the cold as far as understanding our mental health issues and how they related to the rest ot the world (DuBrul 2014, 265).

From the first page of Navigating, DuBrul and McNamara's profound ambivalence toward madness is made vividly apparent. For starters, they write that "madfolks" (to use their term) "share a similarly inspiring and destructive emotional makeup" (DuBrul \& McNamara 2013, 1). In fact, the namesake alone of their organization betrays an ineliminable tragic shadow on their vision - not Daedalus, who flies to safety, nor the phoenix, who resurrects itself after each death, but Icarus, whose flight ends almost immediately in his (permanent) death. As DuBrul and McNamara put it, "Icarus, being young and foolish, was so intoxicated with his new ability to fly that he soared too high" (1). Thus possessed of "double-edged blessings," the mad, according to the editors, "fly dangerously close to the sun — into realms of delusion and psychosis — and crash in a blaze of fire and confusion" (1).

To avoid this fate, DuBrul and McNamara describe themselves as "making the effort to stay balanced and grounded so we can use our powers to make the world we live on better, more 
beautiful, and way more interesting" (DuBrul \& McNamara 2013, 1). This is the positive half of their ambivalence, shining through their description, on the same page, of the "dangerous gift" of madness as something "to be cultivated and taken care of, rather than a disease or disorder to be 'cured' or 'eliminated"' (1). Honoring this ambivalence, the first page closes with DuBrul and McNamara declaring their support of each Icarus member's choice regarding "whether to take psychiatric drugs or not and whether to use diagnostic categories or not" (1). It is to help make these choices informed that the editors compiled Navigating in the first place, a text that is figured as a collection of maps for navigating a life diagnosed as mad within a world gone mad.

In Part 1 of Navigating, "Making Maps to the Other Side," DuBrul and McNamara explain that some of these maps "are constructed by the shows we watch on television and the lessons we learn in classrooms; some are drawn up at our family kitchen tables and on our doctors' desks" (DuBrul \& McNamara 2013, 2). As early as the first page of Part 1, however, the editors complicate — which is, as the word's etymology suggests, a figurative "folding with," such as the folding of a map - this metaphor by claiming that there also exist maps that are carved into a mad person's body. "All the moments of pain and elation," DuBrul and McNamara write, "carve into our terrain with the crooked grace of rivers and ravines" (2). One could visualize this, imaginatively, as an animated, origami human figure, built from the same map materials as the map across which it walks; in short, a map-person navigating a map-world.

As an additional enfolding of their map metaphor, DuBrul and McNamara then relate how, "especially for those of us with thin skin and drastic changes in our personal elation, life is too hard to plot on a grid: the coordinates are always shifting” (DuBrul \& McNamara 2013, 2). This "thin skin" detail is also consistent with my map/person dramatization of their metaphor. Put in the terms of that dramatization, the lines of the map of the mad-person are sometimes in 
rapid motion, while the lines on the map-world appear rigidly static. If one visualizes (a) the former (rapid motion) as the mad body's lines being erased or rubbed out, and (b) the new lines as being carved into the mad person's skin, then it makes sense why madfolks could be so sensitive. DuBrul and McNamara elaborate as follows:

We feel things hard and fast. We feel things quiet and deep. We feel things huge and open. We feel things heavy and slow. Sometimes we don't feel anything at all because we're so busy talking to angels or spies and we check out of what everyone else calls reality for a while (DuBrul \& McNamara 2013, 3).

Connecting this back to the Icarus metaphor, the mad person's feelings push them to shift their focus from their "lined" selves and ground, and to instead reorient themselves toward finding/creating "unlined" beings that are defined by literal or metaphorical flight. Examples of the latter that feature prominently in extreme mental states (including some of those states as recounted in Navigating), are Icarus-winged angels and spies (who, at least in the popular imagination, tend to crisscross the world in aeronautical flight, as with the novelist Ian Fleming's signature character, "James Bond").

Further enfolding the already-enfolded maps of their metaphor, DuBrul and McNamara then compare their composition of Navigating to the act of having "assembled an atlas of maps" (DuBrul \& McNamara 2013, 3). These latter maps, they elaborate, include "some of the underground tunnels beneath the mainstream medical model of treatment, tunnels carved by brave and visionary people before us, and tunnels we're helping to carve ourselves with our friends" (3). Having thus deepened their metaphor to include the subterranean, the DuBrul and McNamara then make another move into the depths, enfolding the metaphor one last time, referring to "maps of our souls as well as the world outside" (3). To recap then, there maps of the 
mad include real and fictional schema and plans (as with television narratives and doctors' advice), traces and narrative of traumatic events, autobiographical monologues and worldly scripts, fantasized flight paths, and diagrams of underground tunnels.

Looking back over Part 1 to Navigating, I draw readers' attention-inspired by Icarus contributor Kika Kat's description of our world as "an elaborate labyrinth of manufactured distraction"- to the existence of an unthematized metaphorical connection between the book's two central metaphors: namely, maps and Icarus (DuBrul \& McNamara 2013, 15). To wit, returning to the Greek mythological origins of the figure of Icarus, it is because he and his father Daedalus were imprisoned in the latter's own creation, the Labyrinth, that Daedalus created the wings for himself and his son in the first place. They were a means of prison liberation. And this Labyrinth was figuratively mapped by Princess Ariadne's thread, which she gave to the hero Theseus to help him find his way back out of the maze (after killing the murderous minotaur).

To see how his use of Ariadne's thread amounts to mapping, simply imagine a child solving a maze puzzle in a coloring book, leaving a bright chromatic trail of wax marking their progress. Now imagine that trail of wax as representing Ariadne's thread as viewed from above, illustrating (from an Icarus'-eye-view) a perfect map of the prison, from its heart to its exit. Connecting this back to Navigating, it is not just the maps of the mad that are value-laden, but also the terrains being mapped, since the latter are prisons, on the model of Daedalus' labyrinth, In fact, this even includes literal prisons, breeding grounds for "psychosis" and inordinate suffering, as well as institutional spaces that are explicitly modeled on psychological studies of prisons, including psychiatric wards, and school classrooms (most infamously in the case of Bentham's Panopticon, as analyzed by Foucault). It is this prison-of-prisons world, where 
madfolks now find themselves imprisoned, which may have been at least part of the cause of the Icarus wings of manic madness (the necessity, if you will, that mothered the wings' invention). A subsequent entry in Navigating solo authored by DuBrul is titled "The Bipolar World." Of relevance to the present investigation, its detailed account of his breakdowns puts pressure on Farber's claim that there is no such thing as mental illness. "The police found me walking on the subway tracks in New York City," DuBrul relates, where he "was convinced the world was about to end and I thought there were microscopic transmitters under my skin that were making me itch and recording everything I was saying for some top-secret branch of the CIA" (DuBrul \& McNamara 2013, 10). Having (at the time) stopped psychiatric drugs altogether, DuBrul later suffered another, similar episode. "The police picked me up, wandering the streets of Los Angeles," he reminisces (11). "I'd been smashing church windows with my bare fists and running through traffic scaring the hell out of people screaming the lyrics to punk songs, convinced that the world had ended and I was the center of the universe" (11).

Having thus foregrounded the suffering and dysfunction of some of his own experiences of debilitating madness, DuBrul closes this essay by exhorting the broader mad community to move beyond the dichotomizing perspectives represented by mainstream psychiatry and antipsychiatry theorists, respectively. "I think it's really about time," DuBrul proposes, that "we start carving some more middle ground with stories from outside the mainstream and creating a new language for ourselves that reflects all the complexity and brilliance that we hold inside" (DuBrul \& McNamara 2013, 14).

Seeking this kind of "new language," the remaining contributions in Navigating (which constitute most of the book) are authored primarily by other contributors to the Icarus Project website. Though there are many valuable insights and poetic brilliance therein, for reasons of 
space I will focus here on what seems to be the most privileged example of that new language.

That is the transformation of people into supernatural beings, especially angels and shamans.

One example of the former, introduced by DuBrul and McNamara's discussion of what the "psychiatric establishment calls 'hypomania' or mild mania," is offered by a contributor who, at the time of Navigating's publication, was a social worker. Going by the epithet "Madliberator," the author recalls how, during an extreme mental episode, he was convinced by his own "theory about the transformation of the earth into the new heaven and wen and women into perfect 'angel creatures"” (DuBrul \& McNamara 2013, 27). ${ }^{4}$

As for the second supernatural figure, the shaman, it is even more prominent in the book. For example, shamanism receives an extended treatment in the final section of Navigating, titled "Drawing New Lines on the Map" (DuBrul \& McNamara 2013, 66). The editors introduce shamanism there as "one of the more imaginative" of the "many lenses through which we can look at the experiences that get labeled mental illness" (67). Immediately after the word shamanism, however, the current (tenth) edition of Navigating appends an asterisk—which is, notably, the only such asterisk in the entire book, which is 84 letter-size pages long. "Since the writing of this piece," DuBrul and McNamara begin in this footnote, "we have become familiar with the complexities of taking a word like shaman from one corner of the world and applying it universally to indigenous healers and guides from many different traditions" (67). Additionally, the editors continue, they are "also aware of the ways that westerners often harm other cultures by adoption the practices and profiting from them," and that, "In a context of cultural

\footnotetext{
${ }^{4}$ In support of Farber's position, this idea resonates with what I have termed the concept of "self-angelizing" in the work of Dante Alighieri, a concept which functions in both a spiritual and a political register, as part of his avowed calling to save readers' souls and restore the world to flourishing peace. See "Dante's Self-Angelizing: A Prophecy of Egalitarian Transhumanism" in Labyrinth: An International Journal for Philosophy, Value Theory, and Sociocultural Hermeneutics 22(2): 139-155.
} 
appropriation and neocolonialism, it's complicated for Westerners to call ourselves shamans" (67). Nevertheless, DuBrul and McNamara conclude, they "still find this language useful if understood as a shorthand for wounded healers with magical or spiritual inclinations," and it was for that reason that they ultimately decided to include these materials, especially because "so many readers of Navigating the Space have found these articles helpful" (67).

Several points here are worth emphasizing, beginning with DuBrul and McNamara's selfawareness, and their solidarity with oppressed Indigenous peoples. Second, their reasoning for continuing to include this shamanic content is democratic, compassionate, and even clinical: namely, honoring the positive impact that these reflections on shamanism have made on the suffering readers of previous editions of Navigating. Finally, and most importantly, these two authors are laying claim to some form of urban/neo-shamanism in the explicit context of courageously naming themselves as "mad," and are thus classifiable (from some perspectives) as psychologically disabled persons. As such, the mad experience their own type of ableist oppression, the survival of which requires additional resources and strategies.

Moreover, the madfolks in Navigating see these two points as connected. "In traditional cultures," DuBrul and McNamara observe, "this [shamanic] ability was seen as a gift, and considered sacred" (DuBrul \& McNamara 2013, 67). Whereas in "modern cultures it is seen as pathology and labeled toxic." The difference between these two kinds of culture is the reason, perhaps, that in "most non-Western cultures, there is not even a word for what we call manic depression." The editors, interpreting this contrast as revealing an immense wrongness in the Western world, then suggest the possibility that "the powers of the shaman could be intensely useful to modern civilization." More specifically, these powers offer "a hope of becoming 
something more than we are - or perhaps it is a hope of emerging into clarity and seeing our world exactly as it is, in all its dimensions" (67).

\section{Tearing Down the Mad World's Prison Walls}

I wish to leave readers with an imaginative scenario that dramatizes my reading of Navigating, and fleshes out my proposal for carrying forward what seems most promising in Farber's mad messianic utopianism. The imagined setting is our world, conceived as Daedalus' labyrinth, understood as a prison world. Imagine, if you will, that the walls of this prisoning maze are high enough that nobody can see over them, and that almost no one can climb them. Additionally, these walls are extremely thin, from the width of a human foot (at their widest) to the near-invisible thinness of a razorblade (at their narrowest).

In this prison world, the so-called "normal people," who according to Farber and the contributors to The Icarus Project, are less sensitive to, and more tolerant of, meaninglessness and injustice, might be perfectly content, or even oblivious to their bondage. But the madfolks in this world would presumably try to scale the walls, attempting to escape, or at least catch a glimpse of the world above and beyond. In this endeavor, and here lies the first upshot of my scenario, the tallest madfolks, and those with the strongest legs, or with the ability to leap the highest would be most successful.

This point recalls Søren Kierkegaard's famous concept of the "leap of faith.” Perhaps the next most famous mad philosopher (if Nietzsche is the most), Kierkegaard is frequently referred to as "the melancholy Dane" (in a nod to Shakespeare's "Hamlet"). Moreover, as I have argued elsewhere, Kierkegaard's "leap" is modeled on dance, on the basis of the etymological connection, also noted by Hegel (among others) between the words "leap" and "dance" in 
multiple languages, including Latin and German (saltare and spielen, respectively). From this perspective, the mad persons in my scenario's prison world would be dancing in leaps, in part to experience a better and freer world..$^{5}$

This connection to dance is also a prominent part of Navigating. At one level, in one casual reference, after his discussion of Huey P. Newton's autobiography (Revolutionary Suicide), DuBrul writes of "learning new dances with the enemy" (DuBrul \& McNamara 2013, 22). In another such casual reference, an Icarus member identified only as "Dalia" evokes "the light-mad dance of moths" (25). At s second level, there are several explicit affirmations of dance in Navigating as a nonverbal source of healing and expression. For example, "When words aren't so accessible,” DuBrul and McNamara explain, “especially when we're dealing with profound depression - we can explore our stories through other forms of expression - art, music, dance" (37). For this reason, they recommend to their readers: "sign up for a dance class and actually go twice a week" (51). At a third level, Navigating offers dance as the ultimate symbol of recovery and creative flourishing, in the following passage:

consistency might seem like a castle in the clouds. This process requires patience, persistence, and a lot of hope. But know that so many of us have been there before, riding the strange strung-out purgatory between the flights and falls of madness and the awkward dance of re-learning to walk - and eventually we all remembered how to dance (DuBrul \& McNamara 2013, 49).

It is therefore true in Navigating that dance, both literal and figurative, is both (a) means of recovery and (b) sign and practice of recovery's highest achievement.

\footnotetext{
5 See Joshua M. Hall, “Religious Lightness in Infinite Vortex: Dancing with Kierkegaard," Epoché: A Journal of the History of Philosophy 23(1): 2018, 125-144.
} 
Returning to my scenario, for further elaboration thereof, suppose that one mad person managed, through such dancing leaps, not merely to see another world, but also to mount the nearest wall. If so, they might discover that there are other people living atop the prison walls, and who might have even constructed makeshift homes thereon. Remembering that some of these walls are extremely (razorblade) thin, one might be recall Gloria Anzaldúa's description of her home as "this thin edge of barbwire" (Anzaldúa 2013, 3). As suggested by the title of Borderlands/La Frontera, the book from which that quote is taken, Anzaldúa's home is constituted by the literal borderland at the Texas/Mexico border, as well as the figurative borderland signified by being a queer woman in that community. In further support of this connection, Anzaldúa also writes of her struggles with madness and medical disability, and her work serves as a helpful reminder that not everyone atop these prison walls would suffer equally. Instead, they would be variously impaired, weighed and wounded by sundry oppressions and traumas, along with corresponding insights and finely honed skills for survival and creation. This community of the mad-liberated, perched precariously atop rope-thin walls, also suggests the famous figures from Nietzsche's Thus Spoke Zarathustra, the madman with the lantern and the tightrope walker (or "rope dancer," to use a more literal translation of the German word, Seiltiinzer). It also suggests Nietzsche's recurring theme of an emerging type of being, the übermensch, more acclimated to heights and risk, and more agile in navigating such terrain. Atop the prison walls, similarly, the most an incarcerated mad-person could hope for would be to find a micro-community of the elite and exceptional. This elite would have the courage and dancelike powers to live on the dangerous heights, where they are always liable to fall back into the prison world, and perhaps too injured by such falls to ever to return to their higher world. Thus, this community could never be for everyone, at least those who remain more human than dancer. 
At this point, however, my scenario already features a considerable accomplishment. It is no small thing, of course, to escape the lower level of such a prison-world. And it is even more difficult to build and sustain a home and community dancing along its precarious walls, ever vulnerable to redescent. Nonetheless, according to theorists such as Farber, (the early) Laing, and (the early) DuBrul and McNamara, this is where the most important work begins. Because if one stops here, the most one can hope for is limited relief for a small minority, and a relief ultimately dependent on the very infrastructure of the mad prison world.

Worse still, my scenario as described thus far has centered primarily on the individual and their extremely limited and fragile support groups. This is not to deny the vital importanceindeed, even survival value — of the latter. Such a centering does, however, leave untouched the even more vital work of political organizing and societal transformation. Put simply, no matter how many madfolks arrive at the micro-community atop the walls, most of the world's mad population (those without the abilities or resources to mount the walls) would remain imprisoned.

In part to make the scenario more robust, in a way that supports such political considerations, I will now incorporate the previously absent fourth dimension. Allowing, that is, for the passage of considerable historical time, suppose that the incarcerated mad people eventually mutate and evolve an additional resource for survival, in the form of wings. And while some folks' wings might be as large as those of Icarus, others' might be just large and strong enough to allow only the lowest and briefest of flights. In fact, these smaller wings would do little more than slow a mad person's fall from the tops of the walls, and afford only a slight lift from the ground, being closer to the wings of a rooster than of an angel. Translating this evolutionary advantage back into Mad Pride terms, folks with the largest and most powerful 
wings, like angels, would be the ones with the most extreme of extreme mental states, like those described by DuBrul, McNamara, and Madliberator. By contrast, those with the smaller wings would be those whom Navigating describe as peaking at "hypomania," like Icarus contributor "Kika Kat," who claims that "I've never been tested for anything or had any diagnosis other than the concern of people who love me" (DuBrul \& McNamara 2013, 15).

This distinction is crucial to this final form of my scenario, because it suggests a reply to Farber's critique of Mad Pride's most visible leadership. To wit, those currently experiencing the most extreme states, without any receiving psychiatric treatment, might indeed be the most visionary among the mad, but they are also — and due to the same factors — often the least effective as leaders for a movement like mad messianic utopianism. More specifically, these extreme angels are the most likely, like the mad namesake Icarus, to fly to unsustainable heights, unable to safely return to the people. For example, DuBrul and McNamara, while they were completely off psychiatric drugs, experienced their most self- and (other-) destructive states. They were in no position, at such times, to lead their own lives, let alone a movement.

There are, however, two other groups of people, represented in my scenario as those with smaller, weaker wings, who might be able to perform such leadership roles. One is composed of people who formerly experienced full mania and involuntary hospitalization, but are currently in recovery without any psychiatric drugs. The other group includes those who only experience "hypomania," and who may not even have received any diagnosis, such as Icarus contributor Kika Kat, and the millions of others like her, both in society as a whole and in the smaller world public intellectuals, academics, artists, and activists affiliated with Mad Pride. With smaller, weaker wings, the people in these two other groups can catch glimpses of the world above walls, and perhaps even ascend to the small communities there, at least for a time. But they are unable 
to fly away completely, and therefore more likely to stay on the ground — at least long enough to gather and organize enough fellow madfolks_-so those hateful prison walls may finally fall. ${ }^{6}$

Toward that end, and by way of conclusion, distill from this scenario four strategies that might be beneficial for leaders of Farber's mad messianic utopianism. First, as the history of religious and political movements suggests, it is often more effective to lead by channeling the spirit of someone with more extreme mental states (than for the leader to have those states or to discipline someone with those states into leadership). For example, Socrates has been interpreted as psychotic (because of his daimon), and it was Plato who channeled his spirit into an attempted reconstruction of the city-state of Syracuse, as well as the revolutionary founding of Academic philosophy. And Jesus has also been interpreted as having psychotic episodes, and it was St. Paul instead who really built the movement in his name. In the case of Mad Pride, Farber might have been more successful had he claimed to channel DuBrul and the Icarus Project into a new phase of the movement, rather than excoriating them for not leading as he would wish. The main challenge to this first strategy, however, is that an aspiring leader may have deep disagreements with their founding/inspiring figure (as with Farber vis-à-vis DuBrul's use of psychiatric drugs), which could limit the leader's ability to wholeheartedly endorse that figure. Alternatively, one might feel pressured to bend the truth and creatively misinterpret the inspiring figure, which might raise ethical questions regarding potential deception and manipulation.

\footnotetext{
${ }^{6}$ Among the latter of these two groups, finally, stands the present author. Following the courageous lead those who have publicly identified as mad (and/or as consumers/survivors/ex-patients), including the contributors to the Icarus Project, and Bradley Lewis, I affirm that I too have experienced milder versions of these extreme states, though (like Kika Kat) I have never had a formal diagnosis, nor been prescribed anti-psychotic drugs. I too have always struggled with what are terms symptoms of depression. And I found myself responding viscerally to DuBrul and McNamara's characterization of (a) "hypomania" as "intoxicating," and (b) how they "tend to become incredibly confident and magnetic to the people around us, and often find ourselves dreaming up grandiose projects and becoming the center of attention" (DuBrul \& McNamara 2013, 26). I acknowledge this in part because, honoring the spirit of Icarus Project's disability rights motto of "nothing about us without us," the leaders of Farber's mad messianic utopianism should be drawn primarily from the high-functioning, self-identified mad.
} 
Second, perhaps the most effective relationship that a leader can have to their movement is that of insider/outsider. As partially inside, such a leader can claim a substantial degree of legitimacy, authenticity, and solidarity with the community. And as partially outside, the leader can also claim access to more objective or impartial perspectives on the community, and possibly also honestly claim to have chosen to affiliate with their disempowered community voluntarily. For example, Kongzi (Confucius) could be seen as an insider/outsider relative to the golden age of Chinese he sought to resurrect (insider as heir to its traditions and reader of its texts, outsider as a historical latecomer). For another, W. E. B. Du Bois was of mixed racial ancestry, with a skin tone and features that enabled him to pass as white in certain settings, and yet he made the choice to identify as Negro in his work for racial justice. In the case of Mad Pride, this might look like a person with milder mad states who can pass as non-mad, such as Bradley Lewis. The primary challenge to this strategy, however, is than insider/outsider may struggle to find genuine acceptance in the community, and be forced to lean heavily on their connections to insiders to offset that unacceptance (the flaws in, and conflict with, such insiders may limit the leader, too).

Third, there is something particularly powerful about the use of dialogues, especially in the form of published correspondence between the leader and their followers in the community, potentially becoming canonical texts of the movement. This is perhaps what Farber intended with the interviews that make up the bulk of his The Spiritual Gift of Madness. And it has been effective in the work of another early member of the Icarus Project, Will Hall, who founded an online radio show called Madness Radio, in which he interviews other mad persons (which were later collected and self-published as Outside Mental Health: Voice and Visions of Madness). The main challenge of this strategy, however, particularly in the case of Mad Pride, is that the followers in these dialogues include many people whose psychological challenges may cause 
them to say counterproductive things, which can undermine their own credibility and the standing of the movement in the larger community. And this, in turn, might prompt a leader to actively filter potential dialogue candidates, and even partially censor the ones chosen, in a way that could be ethically problematic.

Finally, and as a partial counterbalance to the challenges of the first three strategies, the incorporation of aesthetic and literary dimensions into the leader's expressions is a powerful tool. At the level of form, this includes the addition of poetry, prose-poems, and highly poetic prose, and literary tropes such as metaphor, to the ordinary prose that normally dominates such communication. And at the level of content, this includes the incorporation of surreal and magical realist content, such as dream narratives, potential visions, and quasi-vatic streams of consciousness. One major benefit of this approach is that it blurs the boundary between self and other, vehicle and spirit, past and present, thereby allowing a channeling of greater power without having to negotiate either the counterproductive content often attached to that power, or the complex ethical problematics of interpersonal dynamics with existing sources of that power. In the Mad Pride community, one effective practitioner of this technique is the co-founder of the Icarus Project, Jacks McNamara, whose single-author piece in Navigating refers to features my favorite line in the book. They refer there to "the moments when I'd been soaring with eyes full of horizon and a heart branded like a contour map with the outlines of rocky sunrises and the fractal branching of so many threads of understanding" (DuBrul \& McNamara 2013, 5). The main challenge for this final strategy, however, is that the leader's wings may grow too large, taking one too far off the ground, leaving the community lost in this prison world. One must therefore remain mindful of one's artfulness, and not fly so high our feet forget to dance. ${ }^{7}$

\footnotetext{
${ }^{7}$ For, as I have explored in detail elsewhere, in the dance with the people lies the realization of social justice. See, for example, Joshua M. Hall, “On Justice as Dance," Eidos. A Journal for Philosophy of Culture 55(4): 2021
} 


\section{References}

Anzaldúa, G. (2007). Borderlands/La frontera: The new mestiza. San Francisco: Aunt Lute.

Derrida, J. (1996). Remarks on deconstruction and pragmatism. In Chantal Mouffe (Ed.)

Deconstruction and pragmatism (pp. 77-88.) London: Routledge.

DuBrul, S. \& McNamara, J. (2013). Navigating the space between brilliance and madness. New York: The Icarus Project.

DuBrul, S. (2014). “The Icarus Project: A Counter Narrative for Psychic Diversity.” Journal of Medical Humanities 35: 257-271.

Farber, S. (2012). The spiritual gift of madness: The failure of psychiatry and the rise of the mad pride movement Rochester, VT: Inner Traditions.

Hall, W. (2016). Outside mental health: Voices and visions of madness. United States, Madness Radio.

Laclau, E. (1996). Deconstruction, pragmatism, hegemony. In Chantal Mouffe (Ed.) Deconstruction and pragmatism (pp. 47-68.) London: Routledge.

Laing, R. (1967). The politics of experience. New York: Pantheon.

Lewis, B. (2006). Moving beyond Prozac, DSM, and the new psychiatry: The birth of postPsychiatry. Ann Arbor, MI: The University of Michigan Press.

Nietzsche, F. (2006). Thus spoke Zarathustra (Robert Pippin, Ed., Adrian del Caro, Trans.). Cambridge: Cambridge University Press.

Perry, J. (1999). Trials of the visionary mind. Albany, NY: State University of New York Press. Plato. (1995). Phaedrus (A. Nehamas \& P. Woodruff, Trans.). Indianapolis: Indiana University

(forthcoming); "Afro-Latin Dance as Reconstructive Gestural Discourse: The Figuration Philosophy of Dance on Salsa," Research in Dance Education 22(1): 73-87; and "Dancing-with: A Theoretical Method for Poetic Social Justice," Dance and Philosophy, ed. Rebecca Farinas, Craig Hanks, Julie C. Van Camp, and Aili Bresnahan (London: Bloomsbury, 2021), 415-425. 
Press.

Rosenberg, S. and Rosenberg, J., Eds. (2017). Community Mental Health: Challenges for the 21st Century. London: Routledge. 